\title{
Influence of Heat Treatment on the Surface Structure of 6082 Al Alloys
}

\begin{abstract}
N. BAYAT and T. CARLBERG
The $\beta-\mathrm{Al}_{5} \mathrm{FeSi}$ intermetallic phase and coarse $\mathrm{Mg}_{2} \mathrm{Si}$ particles have negative effects on extrudability and workability of 6xxx Al alloys billets. To achieve extruded products with a high surface quality, the as-cast billets are heat-treated before extrusion. During heat treatment, the undesired intermetallic particles, i.e., $\beta$-AlFeSi platelets are transformed to rounded $\alpha-\mathrm{Al}(\mathrm{FeMn}) \mathrm{Si}$ intermetallic phases. Although the heat treatment of the bulk areas of the $6 \mathrm{xxx}$ $\mathrm{Al}$ alloys has been the focus of many previous studies, the process of phase transformation at the very surface has not been paid the same attention. In this study, microstructures of a homogenized billet of a 6082 alloy at the area very close to the surface were investigated. By comparing the X-ray diffraction patterns (XRD) of heat-treated samples as a function of different holding times, the gradual phase transformations could be followed, and using GDOES and map analysis by EDX, the alloying elemental redistribution was analyzed. Partial remelting and porosity growth was detected, and transformation rates were faster than in bulk material and from what is known from industrial processes.
\end{abstract}

DOI: $10.1007 / \mathrm{s} 11661-017-4207-6$

(C) The Author(s) 2017. This article is an open access publication

\section{INTRODUCTION}

6XXX Al alloys are widely used, mainly in extruded form, because of properties such as strengths, ductility, and corrosion resistance. Especially the 6082 alloy, with the highest strength combined with acceptable extrudability, is growing in use in the automotive industry.

The intermetallic particles in the as-cast billets of a 6xxx alloys consist mainly of $\beta$-AlFeSi phase and coarse $\mathrm{Mg}_{2} \mathrm{Si}$ particles. ${ }^{[1-4]}$ The $\beta$-AlFeSi phase is an undesirable phase due to formation of hot cracking and surface defects during subsequent procedures, e.g., extrusion. ${ }^{[5,6]}$ To obtain high surface-quality extruded products, at reasonable extrusion rates, the as-cast billets need to be homogenized before extrusion. ${ }^{[1,2,6]}$

The homogenization temperature, holding time, and cooling rate influence the heat-treated microstructure. ${ }^{[6]}$ Increasing the heat treatment temperature increases both the solubility and the diffusion coefficient, ${ }^{[7]}$ and it is known that the percentage of $\alpha$-phase will be increased by time during homogenization. ${ }^{[8]}$ In addition, different as-cast $\mathrm{Al}$ alloys require varying heat treatment procedures depending on the alloying elements and microstructures. ${ }^{[9]}$

N. BAYAT and T. CARLBERG are with the Department of Natural Sciences, Mid Sweden University, Holmgatan 10, 85170 Sundsvall, Sweden. Contact e-mail: nazlin.bayat@miun.se Manuscript submitted March 23, 2017.

Article published online July 24, 2017
A thick shell zone can affect the surface quality of the extruded products. ${ }^{[10]}$ An as-cast billet should have minimum surface segregation and shell zone in addition to fine secondary phases, fine grains, and cells which are uniformly distributed. ${ }^{[6]}$ If the surface zone is of unacceptable quality scalping of the outer layer is necessary, however, this is a costly treatment and needs to be avoided unless especially strong demands are set on the billet quality.

The surface segregation zone with a thickness of about $100 \mu \mathrm{m}$ in the as-cast billets has higher alloy content compared with the bulk. The concentration of alloy elements at the surface is about five to six times higher than the bulk concentration at smooth surfaces without lapping. ${ }^{[11,12]}$ In previous studies, ${ }^{[12-14]}$ the surface segregation was investigated, and possible mechanisms for surface layer formation during solidification were proposed. However, the changes of the surface zone structure during the homogenization, and the effect of heat treatment on the outer part of the surface layer, have not been thoroughly studied.

Local melting may occur during heat treatment of the billets. In industry, when the cooling rate is high, the last liquid to solidify may contain non-equilibrium eutectic composition. ${ }^{[15]}$ The local melting will take place at the surface layer rather than in the bulk due to higher alloy content and fraction of the eutectic phase.

The surface layer thickness, remelting, and deformation of the billet surface during homogenization as well as the fraction of phase transformation will affect the amount of scrap at the end of the extrusion procedure. 
Hence, investigation of surface layer during heat treatment is of great importance for the DC casting and extrusion industry.

Although many studies have been done on homogenization of the bulk of $6 \times x x$ Al alloys, the process of phase transformation at the very surface has so far not been studied. In the present study, this is done using light optical microscopy, X-ray diffraction (XRD), GDOES, DSC, and SEM with map analyses by EDX.

\section{EXPERIMENTAL PROCEDURE}

A billet of a 6082 alloy with the diameter of $203 \mathrm{~mm}$ was used in this study, and the not scalped surface zone was studied. The composition of the alloy is given in Table I.

Differential scanning calorimetry (DSC), from room temperature to $853 \mathrm{~K}\left(580{ }^{\circ} \mathrm{C}\right)$, was employed to measure the melting point of the as-cast material from the surface and the bulk of a billet. The samples were in the shape of compressed powder obtained by grinding from the surface and bulk areas.

The surface microstructure of the as-cast samples and samples heat-treated at $823 \mathrm{~K}$ and $838 \mathrm{~K}\left(550{ }^{\circ} \mathrm{C}\right.$ and $565{ }^{\circ} \mathrm{C}$ ) were studied. The heat treatments were performed for various time durations for each temperature in order to follow the phase transformations in the best possible way. At $823 \mathrm{~K}\left(550{ }^{\circ} \mathrm{C}\right)$, the times chosen were $4,8,12$, and 16 minutes, in which the phase transformations were completed gradually. At $838 \mathrm{~K}\left(565^{\circ} \mathrm{C}\right)$, the shorter times: 30 seconds, $1,1.5$, and 2 minutes were selected. At the start of the heat treatments the samples, of $3 \mathrm{~mm}$ thickness, were placed in a furnace in which the temperature had been stabilized at the chosen levels. For each temperature and time, direct observations of the surface by scanning electron microscope (SEM) were done, and also corresponding transverse cuts of the same areas were studied by light optical microscope (LOM). Before the cross-sectional studies, the samples were ground and polished mechanically.

Energy dispersive X-ray spectroscopy (EDX) was used to analyze the compositional changes during heat treatment by elemental mapping. Glow discharge optical emission spectroscopy (GDOES) was utilized to study the compositional changes of alloying elements in specific depths from the billet surface, i.e., compositional profiles from the surface.

X-ray diffraction (XRD) (Bruker) technique with a $\mathrm{Cu}_{\alpha}$ source was used to follow and compare the phase transformations at each temperature and time during the heat treatments. The measurements were performed directly on specimens from a billet surface, and in order to have comparable microstructures, the same sample was used for each temperature, i.e., after cooling and
XRD measurements, the sample was transferred back to the furnace for continued heating. At $823 \mathrm{~K}\left(550{ }^{\circ} \mathrm{C}\right)$, the holding times ranged from 4 minutes to 3 hours and at $838 \mathrm{~K}\left(565^{\circ} \mathrm{C}\right)$ the corresponding holding time range was 30 seconds to 10 minutes. For all XRD measurements, the diffraction angles $(2 \theta)$ ranging from 15 to 60 deg were applied, and to obtain the XRD patterns based on random orientation, the sample were rotated $70 \mathrm{rpm}$. The integrated intensity of $\beta$ phase was determined for the strongest and second strongest peaks in XRD measurement patterns of both phases for each temperature and holding time.

\section{RESULTS}

Figure 1 shows the microstructure in transverse cuts of the as-cast and heat-treated samples. As shown in Figure 1(a), the cross section contains long needleshaped particles and eutectic phases. By heat treatment at $823 \mathrm{~K}\left(550{ }^{\circ} \mathrm{C}\right)$ for 4 and 8 minutes (Figures 1 (b) and (c)), the microstructure is changed and in some areas the number of long needle-shaped phases decrease, but also the total segregation layer thickness tends to decrease. As the heat treatment times increase, pores gradually appear and grow, mostly near the surface (Figures 1(b) through (d)), and in addition the secondary phases become more rounded and discrete.

Figures 1(e) through (g) show the structures in transverse cuts of samples heat-treated at $838 \mathrm{~K}\left(565^{\circ} \mathrm{C}\right)$ at different holding times. In Figure 1(e), the segregation layer does not change significantly but some fine pores appear. After holding for 2 minutes (Figure 1(f)), rounded and discrete phases are formed together with more pores, which increase in size after a holding time of 10 minutes (Figure $1(\mathrm{~g})$ ). At this point, the long needle-shaped phases have almost vanished and new rounded particles appear. At both homogenization temperatures, the eutectic areas disappear and are replaced by pores and small globular particles.

Figure 2 illustrates the surface microstructures for the as-cast sample and ones heat-treated at two different temperatures and at various holding times. As visible in Figures 2(a) through (c), the long as-cast phases, which are located at the very surface, are breaking down into separate shorter phases and are partly dissolved (Figure 2(c)). By holding the sample at $823 \mathrm{~K}\left(550{ }^{\circ} \mathrm{C}\right)$ for 16 minutes (Figure 2(d)), the porosity increases and the previous needle-shaped phases vanish, and the surface also shows signs of surface melting.

A similar phase transformation can be observed for the heat-treated samples at $838 \mathrm{~K}\left(565^{\circ} \mathrm{C}\right)$ for $1,1.5$, and 2 minutes (Figures 2(f) through (h)). A certain holding time is required for the transformation to commence, as shown in Figure 2(e), after 30 seconds.

Table I. Chemical Compositions of the 6082 Aluminum Alloy Used in Weight Percent

\begin{tabular}{ccccccccc}
\hline Alloy & $\mathrm{Si}$ & $\mathrm{Fe}$ & $\mathrm{Cu}$ & $\mathrm{Mn}$ & $\mathrm{Mg}$ & $\mathrm{Cr}$ & $\mathrm{Zn}$ & $\mathrm{Ti}$ \\
\hline 6082 & 0.96 & 0.19 & 0.001 & 0.46 & 0.63 & 0.0006 & 0.002 & 0.011 \\
\hline
\end{tabular}



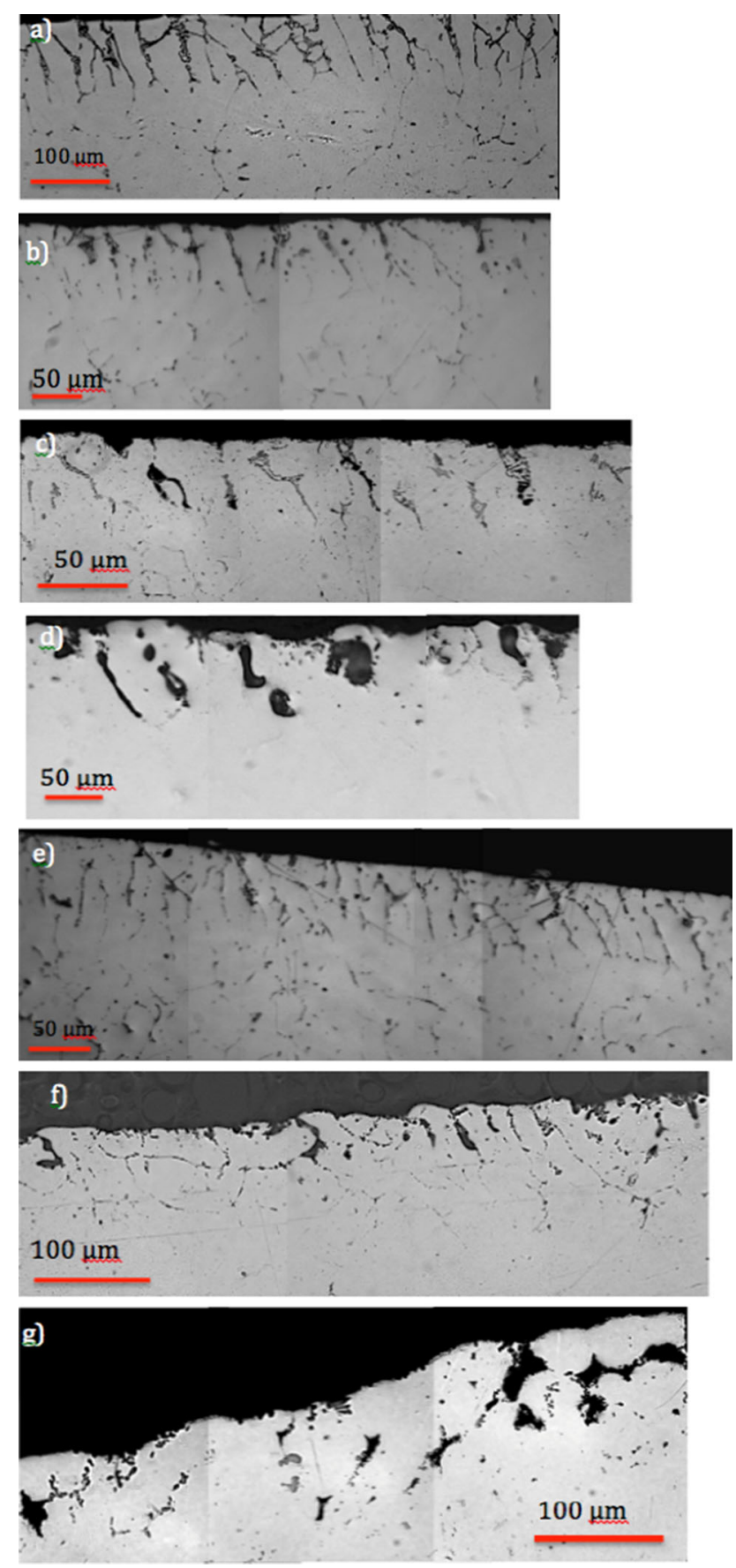

Fig. 1-Cross-sectional LOM images of $(a)$ the as-cast sample and heat-treated samples at $(b) 823 \mathrm{~K}\left(550{ }^{\circ} \mathrm{C}\right)$ for $4 \mathrm{~min},(c) 823 \mathrm{~K}$ $\left(550{ }^{\circ} \mathrm{C}\right)$ for $8 \mathrm{~min},(d) 823 \mathrm{~K}\left(550{ }^{\circ} \mathrm{C}\right)$ for $16 \mathrm{~min},(e) 838 \mathrm{~K}$ $\left(565^{\circ} \mathrm{C}\right)$ for $1 \mathrm{~min},(f) 838 \mathrm{~K}\left(565^{\circ} \mathrm{C}\right)$ for $2 \mathrm{~min}$, and $(g) 838 \mathrm{~K}$ $\left(565^{\circ} \mathrm{C}\right)$ for $10 \mathrm{~min}$.

The needle-shaped structures remain unchanged, but some signs of surface melting appear in certain areas (marked by arrows). After 1 minute of heat treatment, the needles begin to break, and by holding the samples for 1.5 and 2 minutes, the surface roughness (melting) and phase transformations become obvious. However, there are still some needle-shaped particles that require longer heat treatment to completely transform. The formation of pores at the longer holding times becomes clear, but ridges below the former positions of the needle-shaped particles seem to resist melting.

Figures 3 and 4 show EDX map analyses of Si, Mn, $\mathrm{Fe}$, and $\mathrm{Mg}$ for billet surfaces heat-treated at $823 \mathrm{~K}$ and $838 \mathrm{~K}\left(550{ }^{\circ} \mathrm{C}\right.$ and $\left.565{ }^{\circ} \mathrm{C}\right)$. In the as-cast case, Figure 3(a), the presence of $\mathrm{Fe}, \mathrm{Si}$, and $\mathrm{Mn}$ is observed along needle-shaped phases. The presence of $\mathrm{Mg}_{2} \mathrm{Si}$ eutectic structures could be visualized in the figure as areas with $\mathrm{Mg}$. It is obvious that after heat treatment for 8 and 16 minutes the distribution of $\mathrm{Si}, \mathrm{Mn}$, and $\mathrm{Fe}$, originally occurring along the needle-shaped phases, will be spread out over the Al matrix (Figures 3(b) and (c)), especially after 16 minutes. After 8 minutes, some patterns can still be observed, where all elements studied have partly common distributions.

Figure 4 shows samples heat-treated at $838 \mathrm{~K}\left(565^{\circ} \mathrm{C}\right)$ for 1 and 2 minutes. The surface has a mixture of needle-shaped and more rounded phases in dendritic shape.

The Fe, Mn, and Si are still mainly located to these phases after 1 minute, see Figure 4(a), but by heat treatment for 2 minutes, Si spreads out, while Mn and Fe still are strongly located with the dendritic phases (Figure 4(b)). The splitting and transformation of needle-shaped particles to smaller and rounded particles can be followed by looking at the distribution of $\mathrm{Mn}$ and $\mathrm{Fe}$. Zones in which both $\mathrm{Mg}$ and $\mathrm{Si}$ are found are seen at a longer holding time.

GDOES concentration profiles for $\mathrm{Si}$ and $\mathrm{Mg}$ from the surface to the depth of $1 \mu \mathrm{m}$ (Figures 5(a) and (c)), and $120 \mu \mathrm{m}$ (Figures 5(b) and (d)) are shown in Figure 5 for both the as-cast and homogenized samples at different times. The most significant result is that $\mathrm{Mg}$ shows a noticeable increase after heat treatment at 823 $\mathrm{K}\left(550{ }^{\circ} \mathrm{C}\right)$ for 12 minutes at the surface within $1 \mu \mathrm{m}$ (Figure 5(c)). It can also be seen that the content of $\mathrm{Mg}$ decreases at about $20 \mu \mathrm{m}$ from the surface compared to the other profiles on the macro-scale in Figure 5(d). It is clear that the Si content close to the surface is very high, about 20 to $35 \mathrm{wt}$ pct, and decreases somewhat during the homogenization.

In Figure 5(b), a comparison is made with a profile obtained by OES and a step-wise grinding ${ }^{[16]}$ orange curve, showing that it is a good agreement. As the OES data can also be obtained from longer distances from the surface, a total picture of the segregation to the surface zone can be obtained by combining the techniques.

Figure 6 shows data from DSC analyses of unhomogenized 6082 samples taken from the bulk and surface areas. For the surface sample, one endothermic reaction can be observed and it starts at $824 \mathrm{~K}\left(551^{\circ} \mathrm{C}\right)$. For the bulk material, there is no reaction at this temperature, but at $852 \mathrm{~K}\left(579{ }^{\circ} \mathrm{C}\right)$ the signal starts to descend, indicating the solidus temperature.

In Figures 7 and 8, data from XRD measurements for the as-cast and heat-treated samples at $823 \mathrm{~K}$ and $838 \mathrm{~K}$ $\left(550{ }^{\circ} \mathrm{C}\right.$ and $\left.565^{\circ} \mathrm{C}\right)$ with different holding times are shown.

The two strongest $\beta$-peaks are at 17.2 and $24.3 \mathrm{deg}$. It is clear that for both temperatures at increasing holding time the intensities of the $\beta$ peaks are clearly decreasing, 

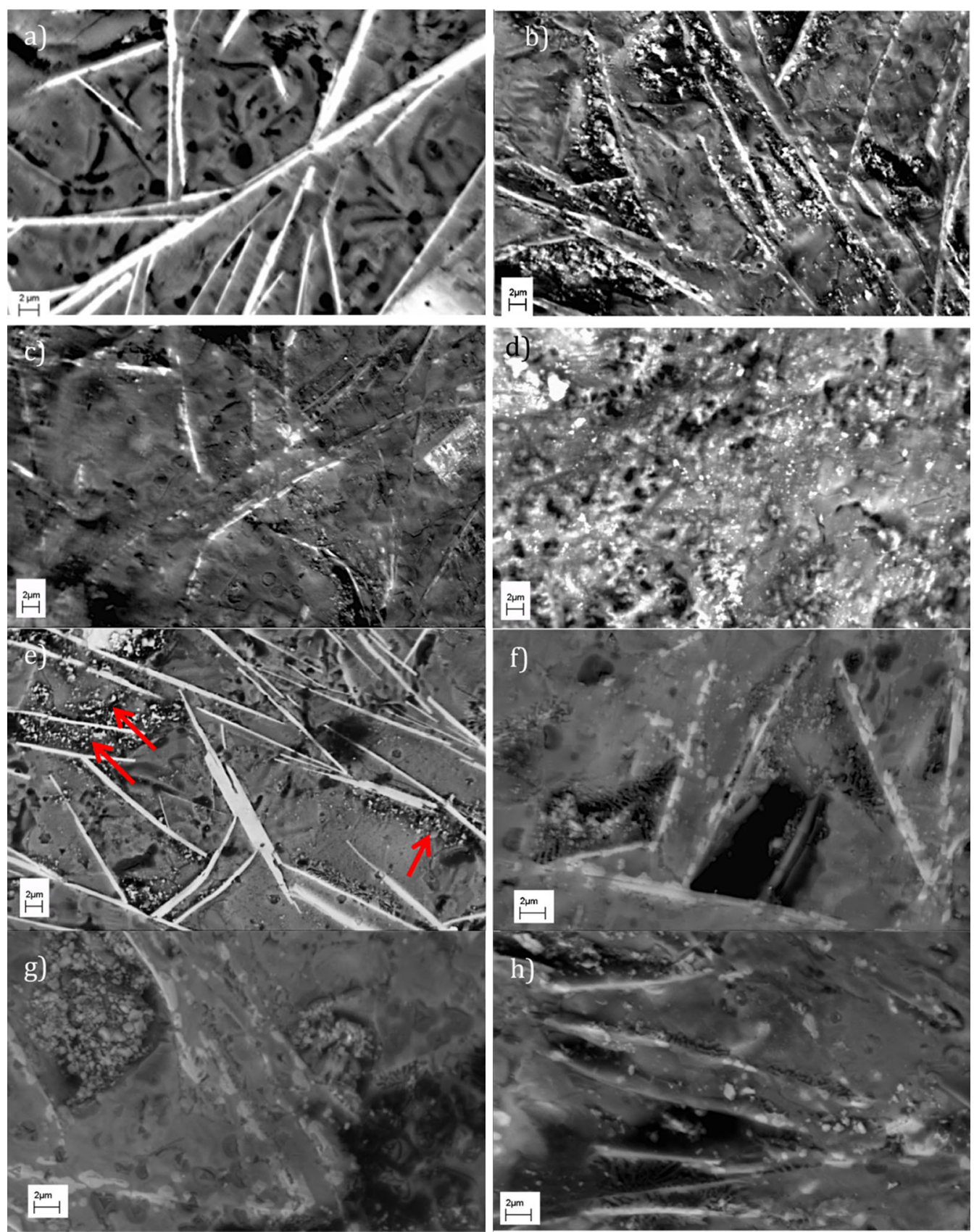

Fig. 2-SEM images of billet surfaces of (a) the as-cast sample and heat-treated samples at $(b) 823 \mathrm{~K}\left(550{ }^{\circ} \mathrm{C}\right)$ for 4 min, $(c) 823 \mathrm{~K}\left(550{ }^{\circ} \mathrm{C}\right)$ for $8 \mathrm{~min},(d) 823 \mathrm{~K}\left(550{ }^{\circ} \mathrm{C}\right)$ for $16 \mathrm{~min},(e) 838 \mathrm{~K}\left(565^{\circ} \mathrm{C}\right)$ for $30 \mathrm{~s},(f) 838 \mathrm{~K}\left(565^{\circ} \mathrm{C}\right)$ for $1 \mathrm{~min},(g) 838 \mathrm{~K}\left(565{ }^{\circ} \mathrm{C}\right)$ for $1.5 \mathrm{~min}$, and $(h) 838 \mathrm{~K}$ $\left(565^{\circ} \mathrm{C}\right)$ for $2 \mathrm{~min}$.

but the $\alpha$-peak intensities are rather constant or slightly increasing.

\section{DISCUSSION}

Similar SEM studies of the billet surface was also reported earlier ${ }^{[13,14]}$; however, the phases, apparently laying on the surface, which can be observed using this technique, were only noted and not explained. The authors of this article have identified the phases in earlier publications ${ }^{[1,12]}$ and discussed their formations. ${ }^{[12]}$ The XRD spectra in the present investigation, Figure 8, confirm the results, and the needleshaped phase is the $\beta$-phase, and the dendritic and globular phases as are the $\alpha$-phase. As can be seen, the transformation from $\beta$ to $\alpha$ phase proceeds at a fast rate in the studied temperature range $823 \mathrm{~K}$ to $838 \mathrm{~K}\left(550^{\circ} \mathrm{C}\right.$ to $\left.565{ }^{\circ} \mathrm{C}\right)$, i.e., in about 15 minutes at $823 \mathrm{~K}\left(550{ }^{\circ} \mathrm{C}\right)$ and in 2 minutes at $838 \mathrm{~K}\left(565^{\circ} \mathrm{C}\right)$. For 6082 alloys, this temperature range is the one used in industry for the homogenization process, but normally the holding times range from 2 to 3 hours. This is probably necessary to accomplish the transformation in the bulk, but 

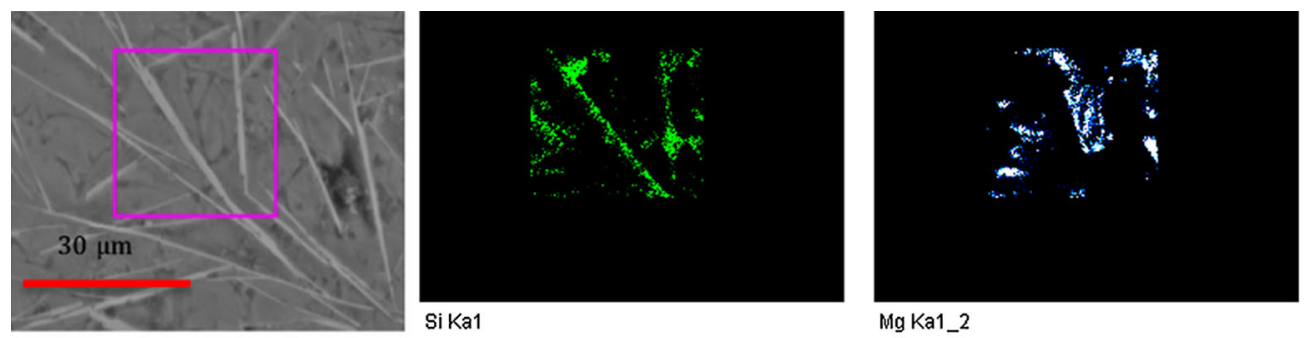

Si Ka1

Mg Ka1_2
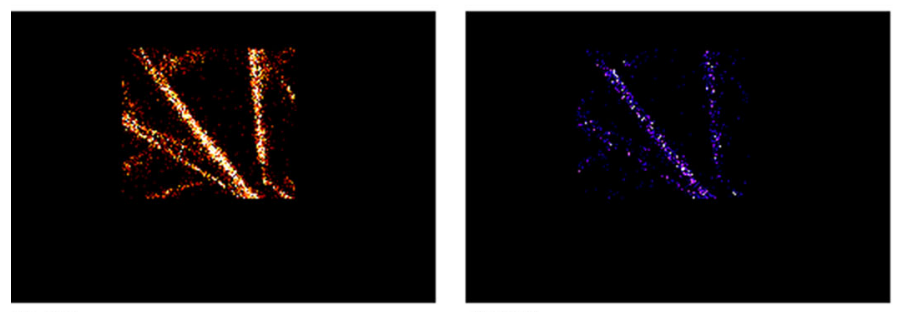

Mn Ka1

(a)
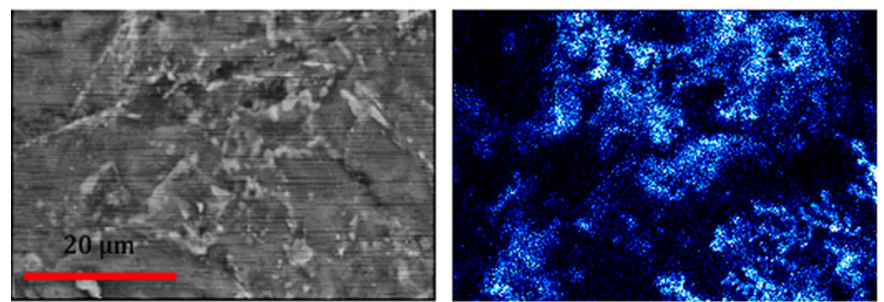

Si Ka1

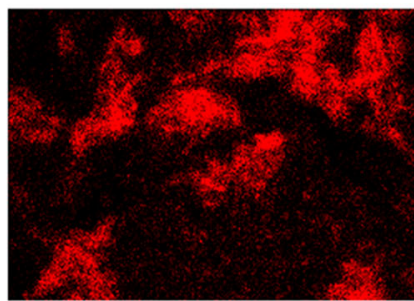

Mg Ka1_2
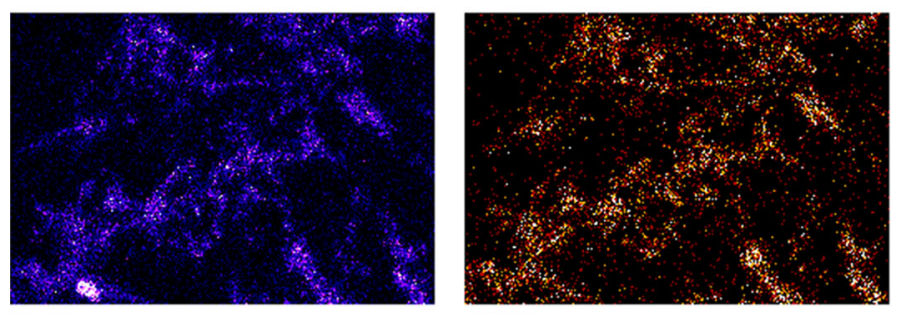

Fe Ka1

(b)

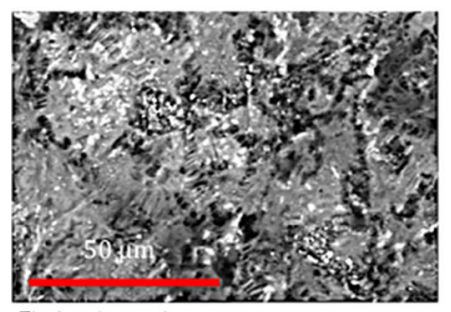

Electron Image 1

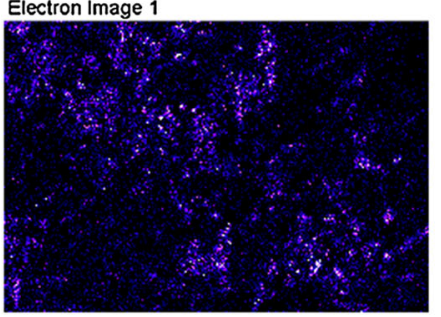

Fe Ka1
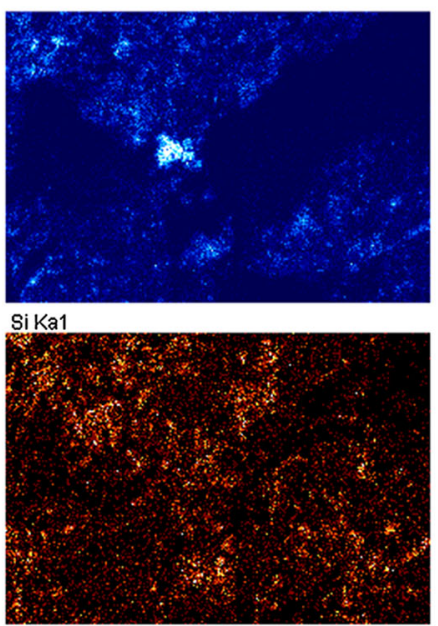

Mn Ka1

(c)

Fig. 3-EDX map analysis of billet surfaces for (a) the as-cast sample and heat-treated samples at $823 \mathrm{~K}\left(550{ }^{\circ} \mathrm{C}\right)$ for $(b) 8 \mathrm{~min}$ and $(c) 16$ min. 


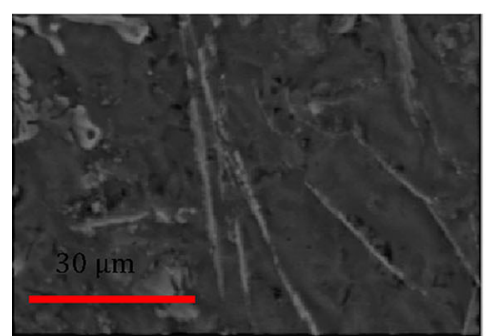

Electron Image 1

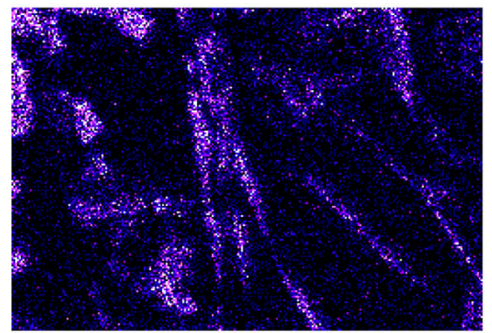

Fe Ka1

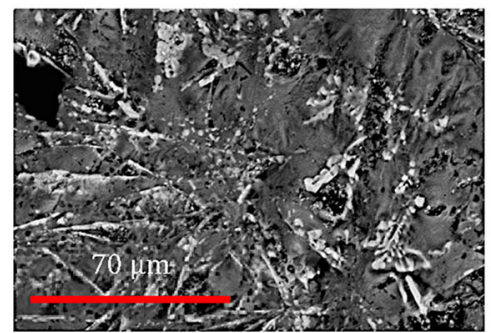

Electron Image 1

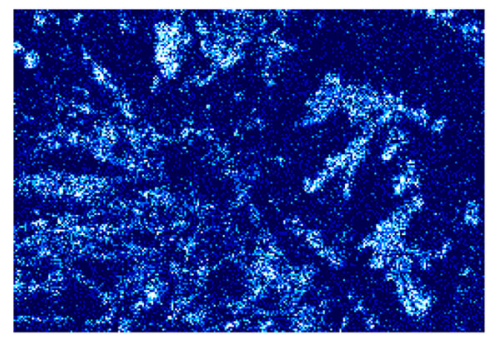

Fe Ka1

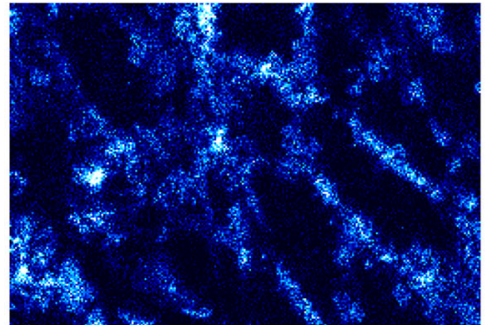

Si Ka1
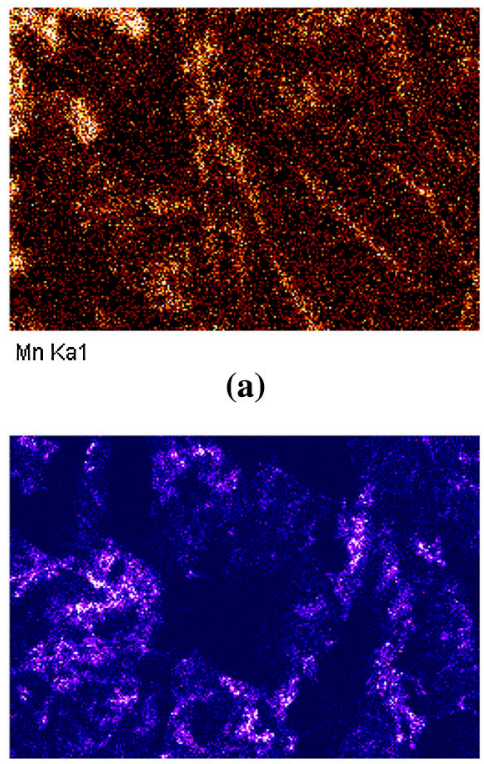

(a)

Si Ka1

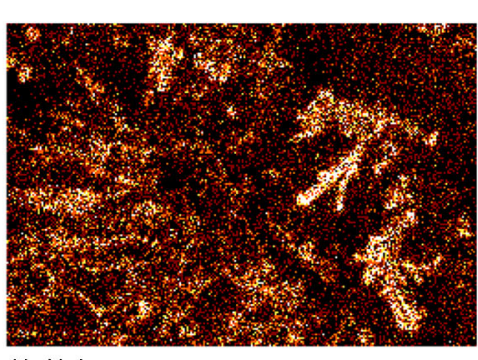

Min Ka1

Mn Ka1

(b)

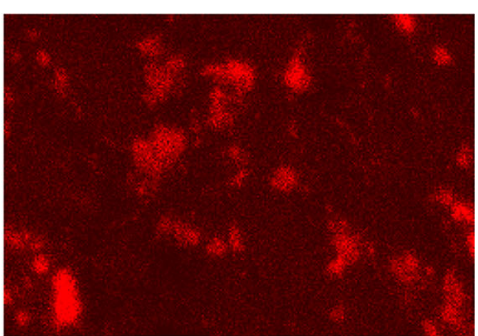

IVI Ka1_2

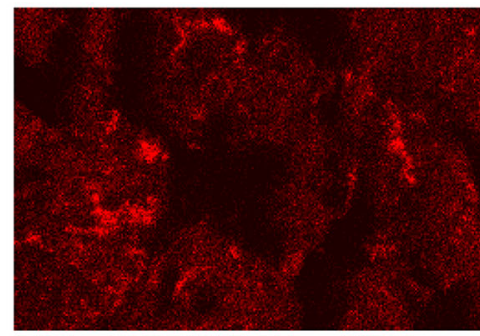

Mg Ka1_2

Fig. 4-EDX map analysis of billet surfaces heat-treated at $838 \mathrm{~K}\left(565^{\circ} \mathrm{C}\right)$ for $(a) 1 \mathrm{~min}$ and $(b) 2 \mathrm{~min}$.

obviously the desired reactions at the surface are much faster.

A problem, inherent in industrial homogenization, is the surface softening of the billets, which causes cladding and damaged surface. The results in Figures 1 and 2 clearly show that the background to the problem is, at the actual temperatures, partial melting occurring with subsequent pore formation. In addition, the DSC results, Figure 6, show that melting occurs for the surface composition and not for the bulk. The DSC curve starts to descend at about $823 \mathrm{~K}\left(550{ }^{\circ} \mathrm{C}\right)$, and the structures from the heat treatments at $823 \mathrm{~K}\left(550{ }^{\circ} \mathrm{C}\right)$ (Figures 1 and 2) shows that partial melting occurs. According to thermodynamic data, the lowest melting temperature for the 6082 alloy is $828 \mathrm{~K}\left(555^{\circ} \mathrm{C}\right)$, but for the highly segregated surface zone this does not seem to be applicable. To avoid the surface melting, the temperature needs to be slightly below $823 \mathrm{~K}\left(550{ }^{\circ} \mathrm{C}\right)$, which is lower than normal industrial practice. This could be a problem, as for lower temperatures the bulk will not transform in reasonable time, e.g., at $813 \mathrm{~K}$ $\left(540{ }^{\circ} \mathrm{C}\right)$, it has been reported that nearly no transformation occurred after 20 minutes. ${ }^{[2]}$

The concentration in the surface zone is a result of segregation during solidification toward the surface and thus very high concentrations are obtained. Making a simple Scheil plot of the segregation, Figure 9 gives an approximation of the level of surface segregation that can be expected. A more exact plot would need an adjustment of the length scale to the actual thickness of 


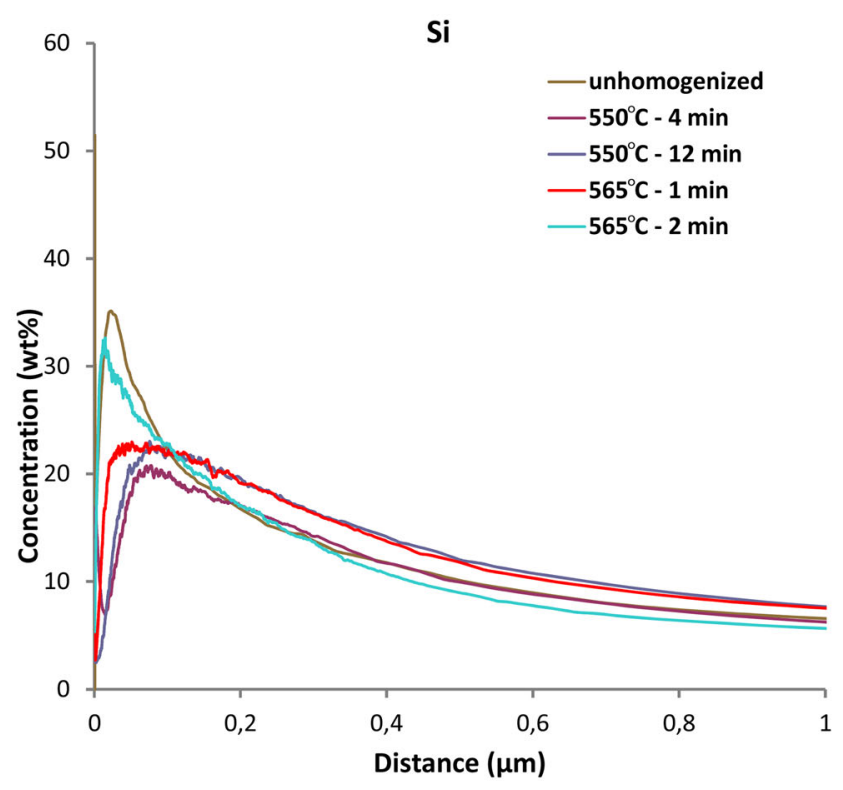

(a)

Si

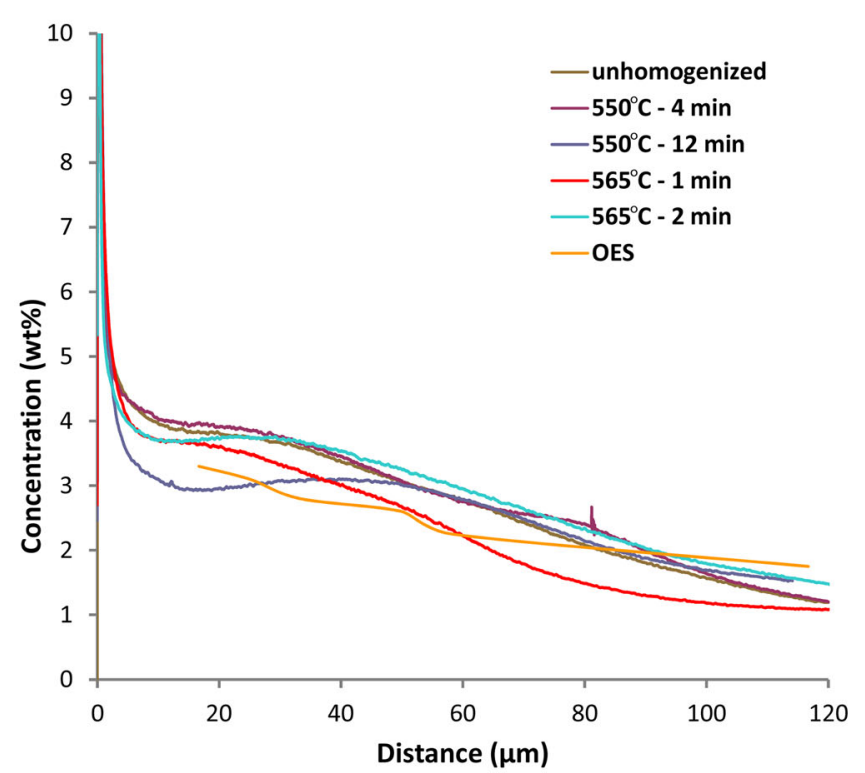

(b)

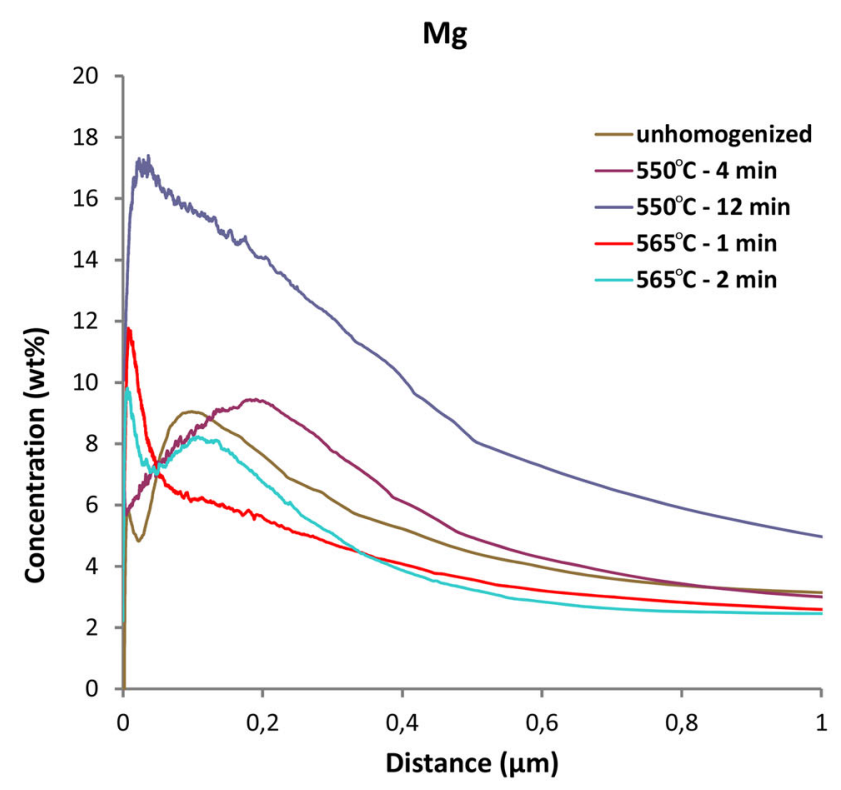

(c)

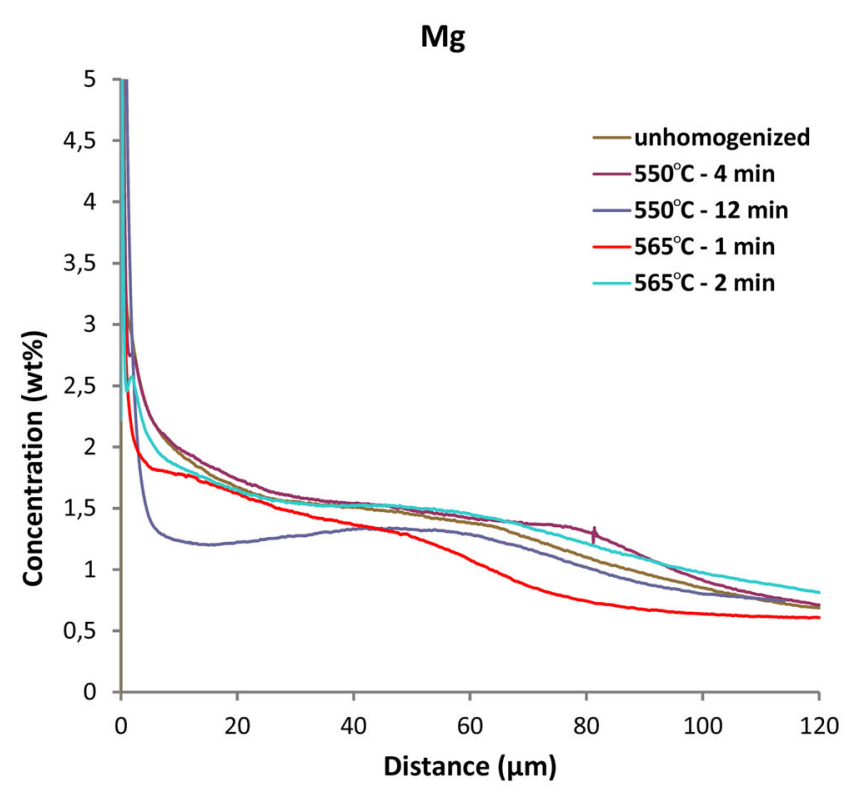

(d)

Fig. 5-GDOES results from the surface of the as-cast and heat-treated samples at $823 \mathrm{~K}$ and $838 \mathrm{~K}\left(550{ }^{\circ} \mathrm{C}\right.$ and $\left.565{ }^{\circ} \mathrm{C}\right)$ for $(a) \mathrm{Si}$ to $1 \mu \mathrm{m}$ and (b) Si to $120 \mu \mathrm{m}$; and (c) Mg to $1 \mu \mathrm{m}$ and (d) Mg to $120 \mu \mathrm{m}$.

the segregation zone, as was done in Reference 11, but already the curves in Figure 9 give a first-order agreement with the GDOES data in Figure 5. The measured data show extremely high concentrations at the surface, i.e., about 35 pet $\mathrm{Si}$, and as the solubility in aluminum is much lower, Si will be found together with $\mathrm{Fe}$ and $\mathrm{Mn}$ in secondary phases, which are apparently laying on the surface. It also means that during the heat treatments the elements cannot back-diffuse into an already saturated matrix, and as shown in Figure 5, so that little change is observed in the depth direction during homogenization.

What happens instead is shown in Figures 1, 2, 3, and 4 , namely a partial melting of eutectics and $\beta$-phase, and a subsequent precipitation of mainly $\alpha$-phase during the cooling. It is therefore not a regular transformation but rather a partial melting and re-solidification, which form the structure shown in Figure $1(\mathrm{~g})$, which is typical for the surface of a homogenized 6082 alloy. The constituents here are not located on the previous $\beta$-particles 


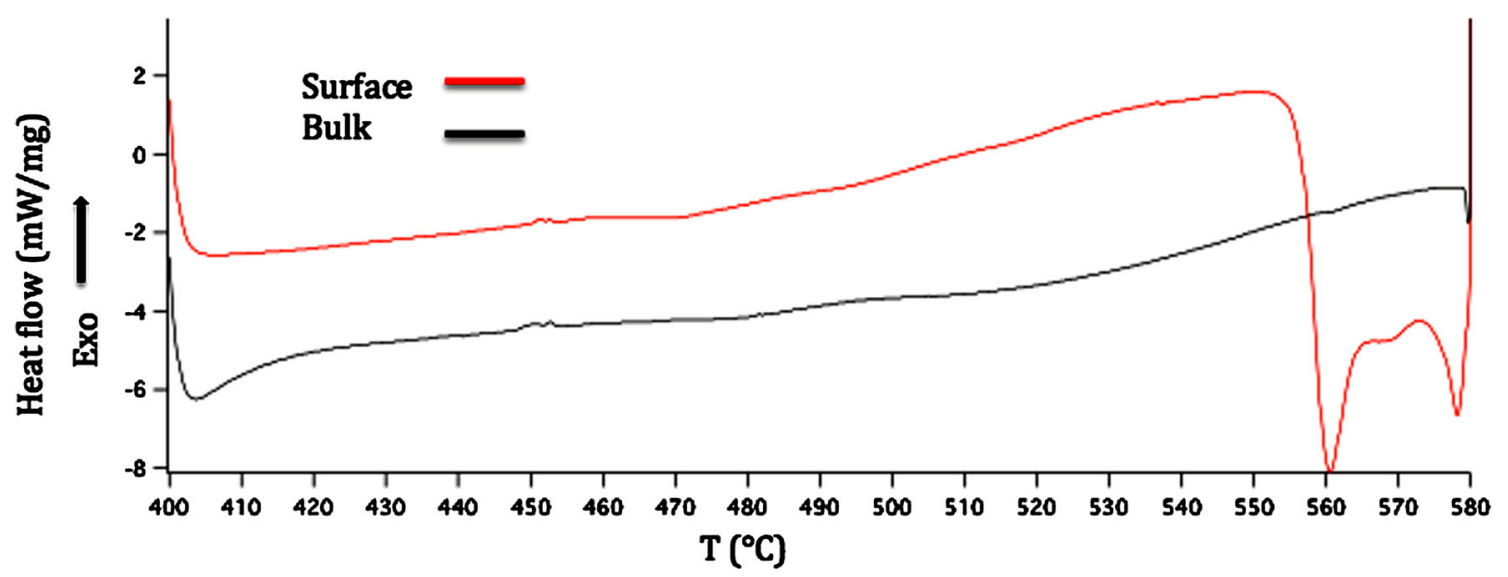

Fig. 6-DSC measurements of the surface and bulk of the unhomogenized sample by heating at $283 \mathrm{~K}\left(10^{\circ} \mathrm{C}\right) \mathrm{min}^{-1}$.

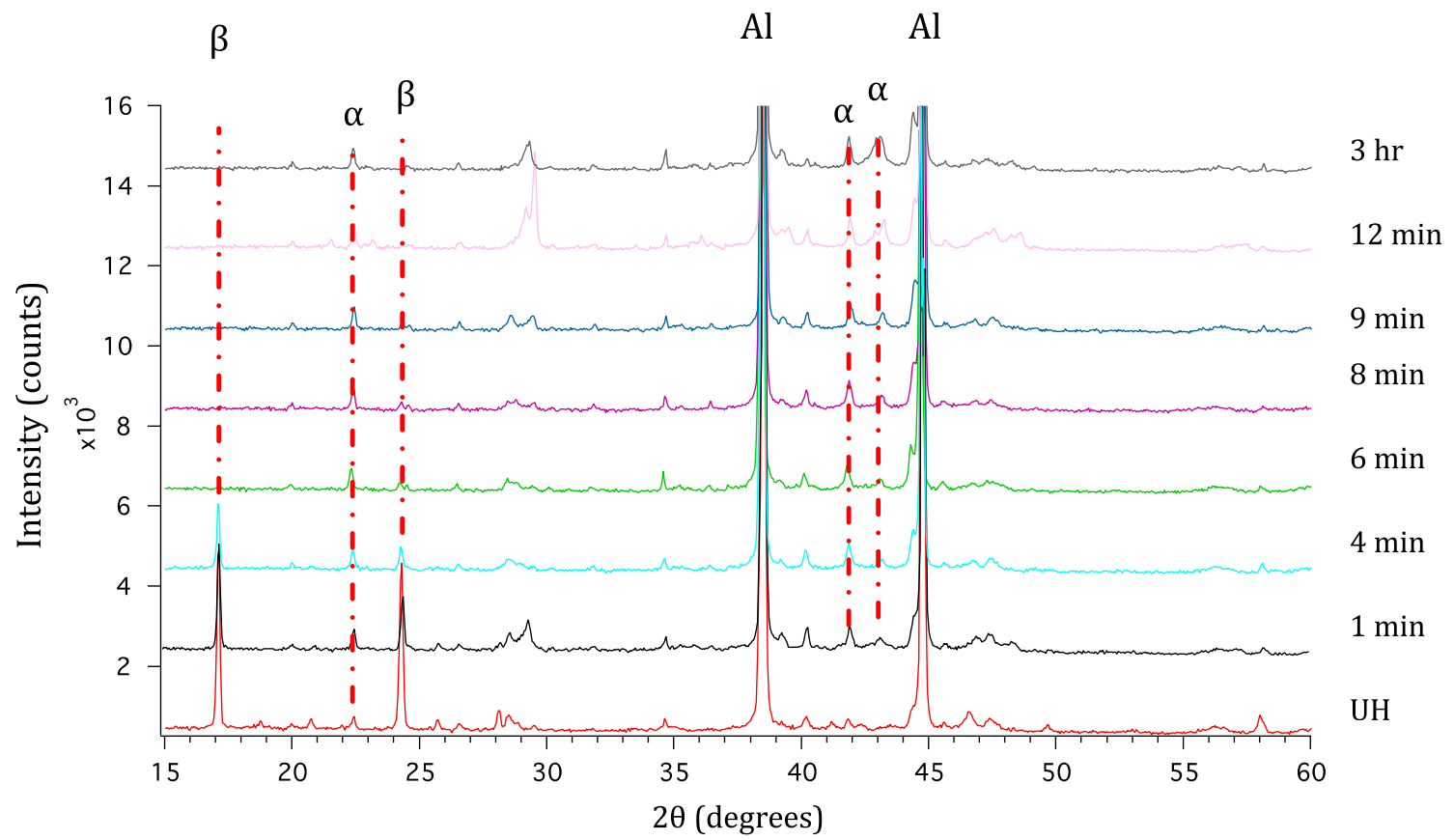

Fig. 7-XRD measurements taken directly on billet surfaces of non-heat-treated samples and samples heat-treated at $823 \mathrm{~K}\left(550{ }^{\circ} \mathrm{C}\right)$ at different times.

patterns but rather laying around pores and on the free surface. In industrially homogenized billets, these particles are both $\alpha$-phase and elemental $\mathrm{Si}$. The $\beta$-phase is totally eliminated during this process and the alloy elements are spread out over the surface and transform into small particles, as seen in Figures 3 and 4. It can also be noted that the $\mathrm{Si}$ and $\mathrm{Mg}$ maps have clear similarities, indicating that precipitation of $\mathrm{Mg}_{2} \mathrm{Si}$ particles could also occur in this process, but could be too small to be observed by LOM.

Regarding the GDOES data, see Figure 5, it should be observed that the measurement points are average compositions over spots of $4 \mathrm{~mm}$ diameter, and, which is inherent with the technique, the measurements are taken at slightly different positions for the different curves. It is possible that some lateral variations on the surfaces could influence the result, although samples were carefully chosen from the same billet area and from spots with the same surface appearance.

The elemental distributions on a hundred micro-scale curves in Figures 5(b) and (d) do not change much during the heat treatments, which means that the alloy element being at the surface remains there during the homogenization and do not back-diffuse, at least not during the time periods studied. The contents of Si for the whole layer are higher than the solubility in solid Al, while the $\mathrm{Mg}$ levels are within the solubility limits at the actual temperatures. A clear result is, however, shown in Figure 5(c) where the $\mathrm{Mg}$ content increases above the solubility limit after 12 minutes. This can be due to $\mathrm{Mg}$ reacting with $\mathrm{Al}_{2} \mathrm{O}_{3}$ on the surface under the formation of $\mathrm{MgO}$ or spinel $\left(\mathrm{MgAl}_{2} \mathrm{O}_{4}\right)$. Similar observations have been done by applying GDOES during studies of $3 \mathrm{xxx}$ alloy surfaces ${ }^{[17]}$ and this oxide replacement has been proposed as a possible reaction. ${ }^{[18]}$ 


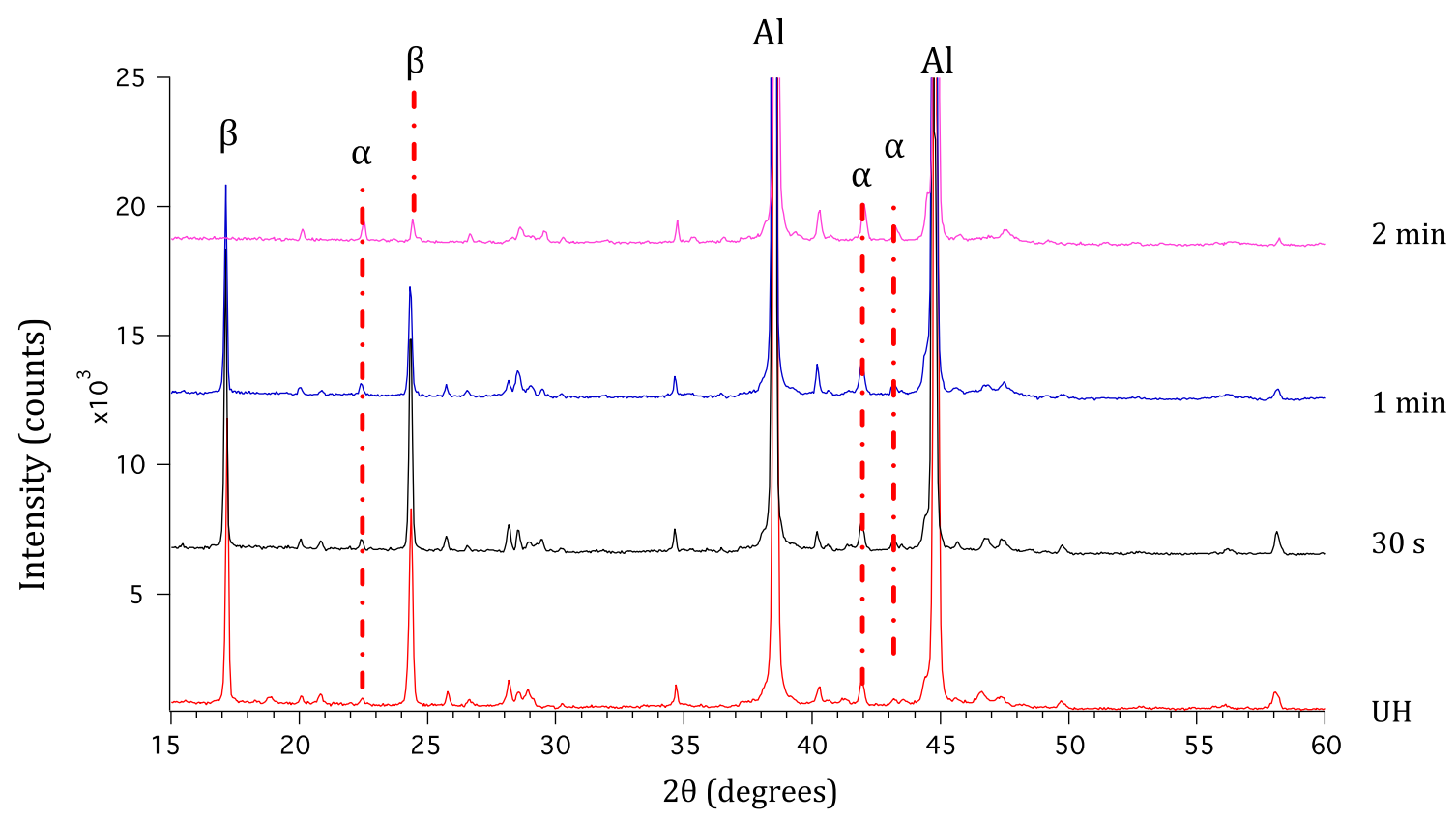

Fig. 8-XRD measurements taken directly on billet surfaces of the as-cast samples and samples heat-treated at $838 \mathrm{~K}\left(565{ }^{\circ} \mathrm{C}\right)$ at different times.

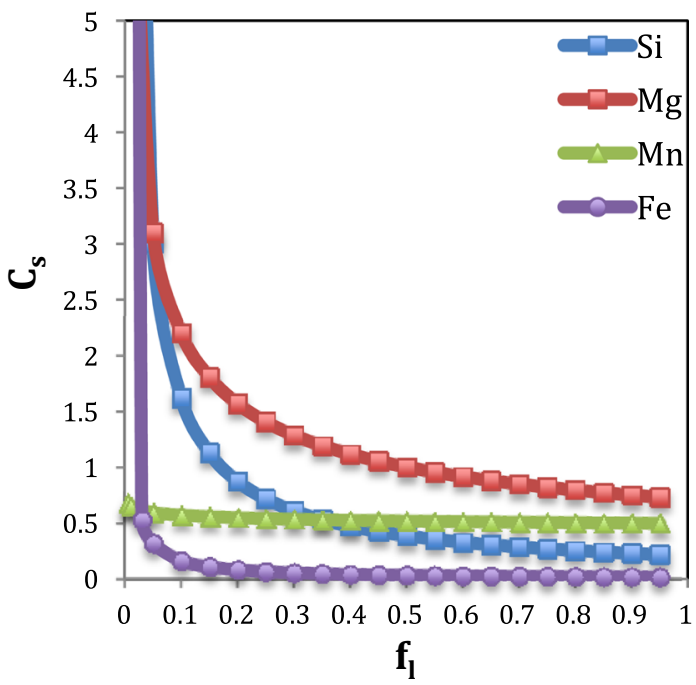

Fig. 9 - Scheil equation calculation for 6082 alloy.

Table II. Peak Area Measurements of the Strongest and Second Strongest $\beta$-Peaks in the XRD Spectra of the Samples Unheat-Treated (UH) and Heat-Treated at Various Homogenization Times at $823 \mathrm{~K}\left(550^{\circ} \mathrm{C}\right)$

\begin{tabular}{llcrc}
\hline Peak Area & UH & 4 min & 8 min & 12 min \\
\hline Strongest $\beta$-peaks & 728 & 239.15 & 4.24 & - \\
Second Strongest $\beta$ peaks & 704.84 & 86.7 & 12.67 & - \\
\hline
\end{tabular}

In many cases, it is important to know when the $\beta$ to $\alpha$-phase transformation is completed, and different techniques have been tested to evaluate this. ${ }^{\left[{ }^{[2]}\right.}$ XRD is one possible technique, and with a penetration depth in Al of about $80 \mu \mathrm{m}$ it is suitable for studies of the
Table III. Peak Area Measurements of the Strongest and Second Strongest $\beta$-Peaks in the XRD Spectra of the Samples Unheat-Treated (UH) and Heat-Treated at Various Homogenization Times at $838 \mathrm{~K}\left(565^{\circ} \mathrm{C}\right)$

\begin{tabular}{lcccl}
\hline & $\mathrm{UH}$ & $30 \mathrm{~s}$ & $1 \mathrm{~min}$ & $2 \mathrm{~min}$ \\
\hline Strongest $\beta$-peaks & 1480.95 & 1435.5 & 1016.49 & - \\
Second Strongest $\beta$-peaks & 1271.19 & 1206.06 & 653.4 & 60.27 \\
\hline
\end{tabular}

segregated surface zone, done in the present research. According to the present XRD measurements, Figures 7 and 8 , both intermetallic phases, $\beta$ and $\alpha$, are found at the segregation zone of the as-cast billets. However, during heat treatment the $\beta$-peaks decrease continuously by increasing holding time, while the $\alpha$ peaks have a more random appearance. This is in contrast to what was observed in bulk material, ${ }^{[2]}$ where the $\alpha$-peaks grew as the $\beta$ peaks disappeared. As has been discussed above, it is likely that in the surface zone there is no gradual $\beta$ to $\alpha$ phase transition, but rather melting of the eutectic and $\beta$-phase followed by precipitation of $\alpha$ during subsequent cooling. The amount of $\alpha$ phase will therefore not be a result of transformation from $\beta$, but rather a new precipitation at every cooling sequence, and this can explain the random size of the $\alpha$ peaks.

The continued decrease of the $\beta$-peaks can be considered quantitatively, and in Tables II and III the peak areas which have been calculated using the IGOR software at $823 \mathrm{~K}$ and $838 \mathrm{~K}\left(550{ }^{\circ} \mathrm{C}\right.$ and $\left.565^{\circ} \mathrm{C}\right)$, respectively, are presented. It can be concluded that the $\beta$-phase has nearly disappeared after 8 minutes of heat treatment at the lower temperature and after 2 minutes at the higher temperature. It can also be concluded that rather little has happened during the first minute at 838 $\mathrm{K}\left(565^{\circ} \mathrm{C}\right)$, but then the melting proceeds quickly. 


\section{CONCLUSIONS}

The study of the segregated layer of a 6082 alloy during heat treatment at $823 \mathrm{~K}$ and $838 \mathrm{~K}\left(550{ }^{\circ} \mathrm{C}\right.$ and $565^{\circ} \mathrm{C}$ ) shows that the phase transformations in the surface zone proceed in much shorter time than the time commonly used for homogenization of billets in industry. This can be attributed to the higher contents of alloying elements at the surface causing local melting. The process at the surface is not a gradual transformation but rather a partial melting and solidification with new phase precipitation during the latter stage.

Gradual pore formations during annealing was also observed, which could be connected to the remelting of eutectic areas and low melting intermetallic particles.

$\mathrm{MgO}$ can partly replace $\mathrm{Al}$ oxide on the surface during homogenization, as the $\mathrm{Mg}$ content at the surface is high.

The melting/dissolution of the $\beta$-phase could quantitatively be followed by XRD measurements directly on the surface.

\section{ACKNOWLEDGMENTS}

Mid Sweden University is acknowledged for financial support, and Kubikenborg Aluminium $\mathrm{AB}$ is acknowledged for providing materials. Docent Joakim Bäckström is acknowledged for support during the XRD measurements.

\section{OPEN ACCESS}

This article is distributed under the terms of the Creative Commons Attribution 4.0 International
License (http://creativecommons.org/licenses/by/4.0/), which permits unrestricted use, distribution, and reproduction in any medium, provided you give appropriate credit to the original author(s) and the source, provide a link to the Creative Commons license, and indicate if changes were made.

\section{REFERENCES}

1. J.H. Li, A. Wimmer, G. Dehm, and P. Schumacher: Phil. Mag., 2014, vol. 94 (8), pp. 830-46.

2. N.C.W. Kuijpers, W.H. Kool, P.T.G. Koenis, K.E. Nilsen, I. Todd, and S. Zwaag: Mater. Charact., 2003, vol. 49, pp. 409-20.

3. G. Sha, K. O'Reilly, B. Cantor, J. Worth, and R. Hamerton: Mater. Sci. Eng. A, 2001, vols. 304-306, pp. 612-16.

4. G. Mrowka-Nowotnik and J. Sieniawski: J. Mater. Process. Technol., 2005, vols. 162-163, pp. 367-72.

5. T. Smith, K. O'Reilly, S. Kumar, and I. Stone: Metall. Mater. Trans. A, 2013, vol. 44A, pp. 4866-71.

6. Y. Birol: Mater. Process. Technol., 2004, vol. 148, pp. 250-58.

7. N.C.W. Kuijpers, F.J. Vermolen, K. Vuik, and S. Zwaag: Mater. Trans., 2003, vol. 44 (7), pp. 1448-56.

8. D.T.L. Alexander and A.L. Greer: Acta Mater., 2002, vol. 50, pp. 2571-83.

9. S. Zajac, B. Hutchinson, A. Johansson, and L.O. Gullman: Mater. Sci. Technol., 1994, vol. 10, pp. 323-33.

10. Y. Birol: Mater. Charact., 2013, vol. 80, pp. 69-75.

11. N. Bayat and T. carlberg: JOM, 2014, vol. 66, No. 5, pp. 700-10.

12. N. Bayat and T. Carlberg: IOP Conference Series, Mater. Sci. Eng., 2016, vol. 117, No. 1.

13. J.C. McCubbin: Light Metal, TMS, 1975, pp. 756-67.

14. S. Benum, A. Håkonsen, and J. Sivertsen: Light Metal, TMS, 1999, pp. 737-42.

15. A.L. Dons: J. Light Met., 2001, vol. 1, pp. 133-49.

16. M. Erdegren and T. Carlberg: Light Metals, 2011, pp. 675-80.

17. S. Kuypers, G. Buytaert, and H. Terryn: Surf. Interface Anal., 2004, vol. 36, pp. 833-36.

18. J.T.B. Gundersen, A. Aytaça, S. Onob, J.H. Nordlienc, and K. Nişancioğlu: Corros. Sci., 2004, vol. 46, pp. 265-83. 